www.jmscr.igmpublication.org

Impact Factor (SJIF): 6.379

Index Copernicus Value: 79.54

ISSN (e)-2347-176x ISSN (p) 2455-0450

crossrefDOI: https://dx.doi.org/10.18535/jmscr/v6i10.236

Journal Of Medical Science And Clinical Research

\title{
A Prospective study on the effects \& prevalence of maternal, fetal \& placental risk factors on low birth weight neonates
}

\author{
Authors \\ Dr J. Raghul ${ }^{1}$, Dr S. Ramesh ${ }^{2}$, Dr S. Chidambaranathan ${ }^{3 *}$ \\ ${ }^{1}$ Post Graduate, Department of Pediatrics, Rajah Muthiah Medical College, Chidambaram \\ ${ }^{2}$ Professor and Head, Department of Pediatrics, Rajah Muthiah Medical College, Chidambaram \\ ${ }^{3}$ Associate Professor, Department of Pediatrics, Rajah Muthiah Medical College, Chidambaram \\ *Corresponding Author
}

Dr S. Chidambaranathan

Email: cdnathan@hotmail.com

\begin{abstract}
Background: Maternal, foetal and placental risk factors have a causative effect in the prematurity and failure to thrive in the early infantile period. Timely diagnosis helps in the anticipation of complications specific to risk factors and managing by impairing their harmful effects on the growth and development of the baby.

Methods: The study was conducted prospectively from January 2018 to July 2018. Neonates $(n=361)$ weighting less than 2.5 kilograms were observed for risk factors and maturity estimation by Dubowitz scoring.

Results: Out of 1040 babies born from January to July 2018, 341 babies weight less than $2.5 \mathrm{~kg}$. Out of which $162(44.88 \%)$ babies were born preterm. Of the full term births 52\% were low birth weightsThe risk factors of the neonates are not mutually exclusive. In the present study 28 maternal risk factors were studied. The prevalence of maternal, fetal and placental risk factors was $85.32 \%, 74.79 \%$ and $6.65 \%$ respectively.

Discussion: India tops the list of 10 nations contributing around $60 \%$ of premature deliveries. Previous preterm delivery, periodontitis, oligohydramnios, gestational diabetes mellitus and maternal short stature were risk factors for pre-term birth, while periodontitis, gestational hypertension and genital infection during the later stages of pregnancy were the independent risk factors for low birth weight.

Conclusion: Period prevalence of low birth weight babies and prematurity is $34.71 \%$ and $15.58 \%$ respectively. Risk factors are not independent to each other with maternal and foetal risk factors have almost have an effect on nearly three fourths of low birth weight neonates.

Keywords: Low birth weight babies, maternal, fetal and placental risk factors.
\end{abstract}

\section{Introduction}

Neonatal mortality rate occupies a major portion of infant mortality rate ${ }^{(1)}$. This is attributed to special problem among neonates, especially congenital anomalies, respiratory tract infections, acute diarrhoeal diseases and skin infections ${ }^{(2)}$.
The increased rate of infections is due to immature immune system and poor functions of integumentary system when compared to those functions in the adults. However, these functions are even more impaired especially in the preterm infants. Preterm biology is unique and considered 
as an equivalent to immune-compromised state despite it is theirs normal physiology ${ }^{(3)}$. Newer advancements in neonatology and foetal medicine aids in the better delivery of health carethereby reducing the neonatal fatality due to prematurity (4). Maternal, foetal and placental risk factors have a causative effect in the prematurity and failure to thrive in the early infantile period ${ }^{(5)}$. These factor either independently or harmoniously with other variables have a deleterious effect on the early part of first year of life ${ }^{(6)}$. Timely diagnosis helps in the anticipation of complications specific to risk factors and managing by impairing their harmful effects on the growth and development of the baby (7)

\section{Methods}

The study was conducted prospectively in Department of Paediatrics, Rajah Muthiah Medical College \& Hospital, Chidambaram from January 2018 to June 2018. Neonates $(n=361)$ weighting less than 2.5 kilograms with parental informed consent are included, whereas those with severe congenital anomaly, systemic disease or infection were excluded from the study. Various known maternal, placental and foetal risk factors are observed during the course of the study. The gestational age of the infants was estimated using modified Dubowitz scoring. Other factors like mode of delivery of the babies were also noted. Statistical analysis (descriptive statistics) was done by using Microsoft word 2010.

\section{Results}

During the study period, 1040 babies were born in which 361 low birth weight babies were included in the study. Period prevalence of low birth weight babies is $34.71 \%$. Out of which $162(44.88 \%)$ babies were born preterm. Among the preterm babies, the prevalence of extreme, early and late preterm was $30.47 \%(n=11), 13.85 \%(n=50)$ and $27.98 \%(n=101)$. In the present study, twenty eight risk factors were analyzed. The risk factors of the neonates are not mutually exclusive. The prevalence of maternal, fetal and placental risk factors was $85.32 \%, 74.79 \%$ and $6.65 \%$ respectively with their distribution in the table- 4 .

\begin{tabular}{|l|c|c|c|c|}
\hline Table-1: Birth weight distribution among neonates \\
\hline \multirow{2}{*}{ Birth weight (Kg) } & $\begin{array}{c}|c| \\
\text { Number } \\
\text { (n) }\end{array}$ & Precentage (\%) & $\begin{array}{c}\text { Number } \\
\text { (n) }\end{array}$ & Precentage (\%) \\
\hline $\begin{array}{l}\text { Extremely LBW } \\
\text { (<1000 gms) }\end{array}$ & 7 & 1.9 & & \\
\hline $\begin{array}{l}\text { Very LBW } \\
\text { (1001 - 1500 gms) }\end{array}$ & 22 & $16 \%$ & & \\
\hline $\begin{array}{l}\text { LBW } \\
(\mathbf{1 5 0 1}-\mathbf{2 5 0 0} \text { gms) }\end{array}$ & 142 & $39 \%$ & 190 & $52 \%$ \\
\hline
\end{tabular}

Table-2: Distribution of maternal risk Factors among low birth weight babies

\begin{tabular}{|l|c|c|c|c|c|c|c|}
\hline S.No & Maternal risk factors & $\begin{array}{c}\text { Preterm } \\
(\mathbf{n})\end{array}$ & $\begin{array}{c}\text { Preterm } \\
\mathbf{\%}\end{array}$ & $\begin{array}{c}\text { Term } \\
(\mathbf{n})\end{array}$ & $\begin{array}{c}\text { Term } \\
\mathbf{\%}\end{array}$ & $\begin{array}{c}\text { Total } \\
(\mathbf{n})\end{array}$ & $\begin{array}{c}\text { Total } \\
\mathbf{\%}\end{array}$ \\
\hline 1 & Anemia & 2 & .5 & 11 & 85 & 13 & 3.6 \\
\hline 2 & $\begin{array}{c}\text { Pregnancy induced } \\
\text { hypertension }\end{array}$ & 9 & 2.4 & 17 & 4.7 & 26 & 7.2 \\
\hline 3 & Gestational diabetes & 6 & 1.65 & 9 & 2.4 & 15 & 4.1 \\
\hline 4 & Hypothyroid & 8 & 2.2 & 10 & 2.7 & 18 & 4.9 \\
\hline 5 & Eclampsia & 1 & .2 & 2 & .55 & 3 & .83 \\
\hline 6 & Pre-eclampsia & 5 & 1.3 & 4 & 1.1 & 9 & 2.4 \\
\hline 7 & Seizure disorder & - & - & 1 & .27 & 1 & .22 \\
\hline 8 & Varicella & - & - & 1 & .27 & 1 & .27 \\
\hline 9 & HBsAg positive mother & 1 & .2 & - & - & 1 & .27 \\
\hline 10 & TORCH infections & 1 & .2 & - & & 1 & .22 \\
\hline 11 & Oligohydraminos & 26 & 7.2 & 53 & 14.6 & 79 & 21.88 \\
\hline
\end{tabular}




\begin{tabular}{|l|l|c|c|c|c|c|c|}
\hline 12 & $\begin{array}{l}\text { Prolonged rupture of } \\
\text { membranes }\end{array}$ & 19 & 5.2 & 23 & 6.4 & 42 & 11.63 \\
\hline 13 & Chronic hypertension & 3 & .8 & 1 & .2 & 4 & 1.1 \\
\hline 14 & Cervical fibroid & 1 & .2 & & & 1 & .2 \\
\hline 15 & Short primi & 2 & .5 & 1 & .2 & 3 & .83 \\
\hline 16 & Rh negative & 2 & .5 & 5 & 1.3 & 7 & 1.9 \\
\hline 17 & Breech & 2 & .5 & 3 & .8 & 5 & 1.3 \\
\hline 18 & Polyhydraminos & 6 & 1.6 & 14 & 3.8 & 20 & 5.5 \\
\hline 19 & Heart disease & - & & 3 & .8 & 3 & .83 \\
\hline 20 & Asthma & 1 & .21 & 2 & .8 & 3 & .83 \\
\hline 21 & Teenage pregnancy & 1 & .21 & - & .2 & 1 & .2 \\
\hline 22 & Overt Diabetes & 2 & .5 & 1 & .8 & 3 & .83 \\
\hline 23 & VDRL positive mother & - & - & 1 & .2 & 1 & .2 \\
\hline 24 & Infertility & 4 & 1.1 & - & .3 & 4 & 1.1 \\
\hline 25 & Renal calculi & - & & 1 & .2 & 1 & .2 \\
\hline 26 & UTI & 1 & .2 & 1 & .25 & 2 & .55 \\
\hline 27 & Pulmonary tuberculosis & 1 & .2 & - & .2 & 1 & .2 \\
\hline 28 & $\begin{array}{l}\text { Lower } \\
\text { infections }\end{array}$ & 1 & .2 & 2 & .3 & 3 & .83 \\
\hline
\end{tabular}

\begin{tabular}{|l|c|c|c|}
\hline \multicolumn{4}{|c|}{ Table-3: Dubowitz scoring distribution table } \\
\hline S.No & Dubowitz score & Number (n) & Percentage (\%) \\
\hline 1 & $28-30$ weeks & 11 & 3.05 \\
\hline 2 & $30-32$ weeks & 18 & 4.99 \\
\hline 3 & $32-34$ weeks & 32 & 8.86 \\
\hline 4 & $34-36$ weeks & 101 & 27.98 \\
\hline 5 & $36-38$ weeks & 199 & 55.12 \\
\hline
\end{tabular}

Table-4: Distribution of Foetal Placental Risk Factors among Low Birth Weight Babies

\begin{tabular}{|l|c|c|c|c|c|c|}
\hline Placental risk factors & \multicolumn{2}{|c|}{ Pre-term } & \multicolumn{2}{c|}{ Term } & \multicolumn{2}{c|}{ Total } \\
\hline Placenta previa & 2 & 0.55 & 10 & 2.77 & 12 & 3.32 \\
\hline Abruptio placenta & 4 & 1.11 & 1 & 0.28 & 5 & 1.39 \\
\hline Fetoplacental insufficiency & 2 & 0.55 & 5 & 1.39 & 7 & 1.94 \\
\hline Fetal risk factors & \multicolumn{2}{|c|}{ Pre-term } & \multicolumn{2}{c|}{ Term } & \multicolumn{2}{c|}{ Total } \\
\hline Pre-term & 158 & 43.77 & 0 & 0.00 & 158 & 43.77 \\
\hline IUGR & 0 & 0.00 & 48 & 13.30 & 48 & 13.30 \\
\hline VLBW & 32 & 8.86 & 0 & 0.00 & 32 & 8.86 \\
\hline Twin & 19 & 5.26 & 5 & 1.39 & 24 & 6.65 \\
\hline Congenital defects & 5 & 1.39 & 2 & 0.55 & 7 & 1.94 \\
\hline TORCH infections & 1 & 0.28 & 0 & 0.00 & 1 & 0.28 \\
\hline
\end{tabular}

\section{Discussion}

UNICEF's data implies that about $28 \%$ of babies of India are born low in birth weight. In India 6 to 8 million low birth weights are yearly. Of these 7.5 million babies, $60 \%$ are term with foetal growth retardation while the remaining $40 \%$ are pre-term. Action report on preterm birth in India 2013 documented that the country accounted for 3.6 million viz., $24 \%$ of global pre-term births. India stands first among 10 nations contributing around $60 \%$ of premature deliveries ${ }^{(8)}$. In a study conducted by ahankari et al, the hospital inbirths were compiled from1st January, 6\% were preterm deliveries, $13.8 \%$ were low birth weight deliveries. Multigravida women has a lower risk of low birth weight when compared with primigravida. Anemia was common in $91 \%$ of women tested. Elderly primi mothers have a higher incidence of low birth weight in rural Indian settings. Lei et al conducted study in china 
in 2013. In that study 28045 live infants were included. 2845 PIH women were included. These $\mathrm{PIH}$ women are at a higher risk of attaining low birth weight when compared with antenatal mothers who don't have gestational hypertension $^{(10)}$. In a study conducted by Chaitanya et al, 709 antenatal mothers with risk factor of dental infections and genitourinary infections were included. Rates of preterm birth and low birth weight in the study population were $7.6 \%, 11.4 \%$ respectively. Previous pre-term delivery, periodontitis, oligohydramnios, gestational diabetes mellitus and maternal short stature were risk factors for pre-term birth, while periodontitis, gestational hypertension and genital infection during the later stages of pregnancy were the independent risk factors for low birth weight. In another study antenatal women were ggiven green leafy vegetables and fruit.Among 2291 antenatal mothers, 1360 neonates were included. In 1094 newborns whose mothers started supplementation > 90 days before pregnancy, birth weight was higher in the treatment group ${ }^{(11)}$.

\section{Conclusion}

Period prevalence of low birth weight babies and prematurity is $34.71 \%$ and $15.58 \%$ respectively. Risk factors are not independent to each other with maternal and foetal risk factors have almost have an effect on nearly three fourths of low birth weight neonates.

\section{References}

1. Ouyang F, Parker M, Cerda S, Pearson C, $\mathrm{Fu}$ L, Gillman MW, et al. Placental weight mediates the effects of prenatal factors on fetal growth: The extent differs by preterm status. Obesity. 2013;21(3):609-20.

2. Leung JC, Cifra CL, Agthe AG, Sun CCJ, Viscardi RM. Antenatal factors modulate hearing screen failure risk in preterm infants. Arch Dis Child Fetal Neonatal Ed. 2016;101(1):F56-61.

3. Kunjunju AM, Gopagondanahalli KR, Chan Y, Sehgal A. Bronchopulmonary dysplasia-associated pulmonary hypertension: Clues from placental pathology. J Perinatol. 2017;37(12): 1310-4.

4. Kazzi SNJ, Jacques SM, Qureshi F, Quasney MW, Kim UO, Buhimschi IA. Tumor necrosis factor- $\alpha$ allele lymphotoxin- $\alpha+250$ is associated with the presence and severity of placental inflammation among preterm births. Pediatr Res. 2004;56(1):94-8.

5. Harteman JC, Nikkels PGJ, Kwee A, Groenendaal F, De Vries LS. Patterns of placental pathology in preterm infants with a periventricular haemorrhagic infarction: Association with time of onset and clinical presentation. Placenta. 2012;33(10): 83944.

6. Chiarelli S, Zanardo V, Ouyang F, Parker M, Cerda S, Pearson C, et al. Perinatal factors associated with the neurologic impairment of children born preterm. Obstet Gynecol. 2008;101(1):553-7.

7. Zanardo V, Vedovato S, Suppiej A, Trevisanuto D, Migliore M, Di Venosa B, et al. Histological Inflammatory Responses in the Placenta and Early Neonatal Brain Injury. Pediatr Dev Pathol. 2008;11(5):350-4.

8. Viscardi RM, Muhumuza CK, Rodriguez A, Fairchild KD, Sun CCJ, Gross GW, et al. Inflammatory markers in intrauterine and fetal blood and cerebrospinal fluid compartments are associated with adverse pulmonary and neurologic outcomes in preterm infants. Pediatr Res. 2004;55(6):1009-17.

9. Ahankari A, Bapat S, Myles P, Fogarty A, Tata L. Factors associated with preterm delivery and low birth weight: a study from rural Maharashtra, India. F1000Research. 2017;6(May):72.

10. Lei F, Liu D, Shen Y, Zhang L, Li S, Liu $X$, et al. Study on the influence of pregnancy induced hypertension on 
neonatal birth weight. J Investig Med. 2018;66(6):1008-14.

11. Tellapragada C, Eshwara VK, Bhat P, Acharya S, Kamath A, Bhat S, et al. Risk factors for preterm birth and low birth weight among pregnant Indian women: A hospital-based prospective study. J Prev Med Public Heal. 2016;49(3):165-75. 